\title{
NEW RECORDS AND PRESENT STATUS OF THE INVASIVE SPOTTED WING DROSOPHILA, DROSOPHILA SUZUKII (MATSUMURA, 1931) (DIPTERA) IN HUNGARY
}

\author{
Gábor Dániel Lengyel ${ }^{1}$, Szilvia Orosz ${ }^{2}$, Balázs Kiss ${ }^{1}$, Réka Lupták ${ }^{1}$ and Zsolt Kárpáti ${ }^{1}$ \\ ${ }^{1}$ Plant Protection Institute, Centre for Agricultural Research, Hungarian Academy of Sciences \\ H-1525 Budapest, P.O. Box 102, Hungary \\ E-mails: lengyel.gabor@agrar.mta.hu,kiss.balazs@agrar.mta.hu \\ luptak.reka@agrar.mta.hu,karpati.zsolt@agrar.mta.hu \\ ${ }^{2}$ Plant Health and Molecular Biology National Reference Laboratory \\ National Food Chain Safety Office, Directorate of Plant Protection, Soil Conservation \\ and Agri-environment, H-1118 Budapest, Budaörsi út 141-145, Hungary \\ E-mail:oroszsz@nebih.gov.hu
}

The spotted wing drosophila (Drosophila suzukii (Matsumura, 1931) - SWD) is one of the most recently introduced invasive pests of economical importance in Europe. It has invaded many countries in Europe and North America causing significant losses in fruit production. In 2012, the species has been detected for the first time in Hungary at a highway rest area. The following year a countrywide trapping program was conducted to monitor the spreading of the species. In 2013, thirty-three highway rest areas and furthermore cherry, strawberries, raspberries, peach, grape orchards were monitored using apple vinegar bait traps. Altogether 33 individuals of SWD have been captured in 5 localities along highways in western Hungary, including the collecting site of the first detection. On the other hand the species was not found in countryside orchards.

The location of the collecting sites indicates that international transport along highways plays an important role in spreading of SWD. Highway infrastructures, like selective trash bins, or buildings may serve as refugee spots for SWD. The role of vehicle transport in the spreading of SWD is also supported by the relatively high spreading rate of SWD, which was estimated around 320-390 km year-1.

Key words: invasive species, Diptera, Drosophila suzukii, Hungary, road ecology, spreading.

\section{INTRODUCTION}

The spotted wing drosophila (Drosophila suzukii (Matsumura, 1931) SWD) belonging to the fruit fly family (Drosophilidae) is a pest of fruit production in North America and Europe (WALsh et al. 2011). Its major host plants are fruit crops with thin and soft fruit skin, such as berries (Rubus spp., Vaccinium spp., Fragaria spp.), cherries (Prunus avium), peach (P. persica), apricot ( $P$. armeniaca) (Cini et al. 2012) and grape vine (Vitis vinifera) (Grassi et al. 2011).

The native range of the species is uncertain, but it was only reported from East Asia (Japan, South Korea, China, Pacific Islands) up until the 1980s 
(B̈̈chli \& Rocha Pité 1984). It was introduced to Europe (Cini et al. 2012) and North America (HAuser et al. 2009; SтECK et al. 2009) in 2008 and began to spread very quickly. Within five years the species successfully reached 13 countries in Europe (Table 1, Fig. 2); the western coast of North America from Mexico to British Columbia; and the eastern coast from Florida to Quebec (HAuser 2011).

In 2012, SWD appeared in Hungary. One male and two females of SWD were caught by a bottle trap baited with apple cider vinegar in a highway rest area (Kiss et al. 2013). Based on this result, a countrywide trapping program was designed to monitor the spreading of the species in Hungary. The surrounding orchards and vineyards of the first detection place were monitored and complementary samplings have been started countrywide by the National Food Chain Safety Office (NÉBIH) in 2013 (Fig. 1 - diamonds).

\section{MATERIAL AND METHODS}

In 2013, 33 traps were placed in 33 rest areas along five Hungarian highways (M1, M3, M5, M7, M0) to capture drosophilids (Fig. 1). Traps were made of $500 \mathrm{ml}$ plastic, soft drink bottles containing 20-25 holes (diameter $3 \mathrm{~mm}$ ) on the side nearest to the top to allow

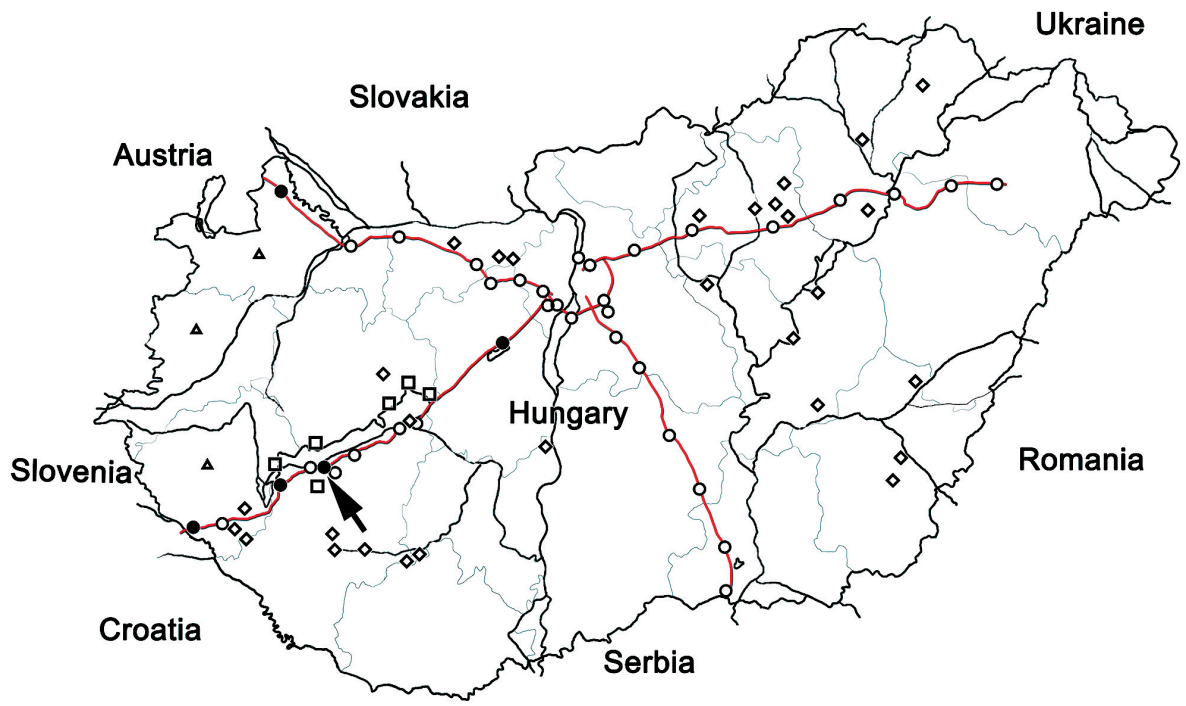

Fig. 1. Monitoring sites for Drosophila suzukii in Hungary in 2012-2013. Filled symbols show positive catch results in 2013, while unfilled symbols represent unsuccessful samplings for SWD. Legend: circles = traps at highway rest areas in 2012-2013; squares = traps only in 2012; diamonds = traps placed by NÉBIH (National Food Chain Safety Office) in 2013. The arrow indicates the locality of the first detection of SWD in Hungary in 2012 (for details on trapping procedure in 2012 see Kiss et al. 2013). 
Table 1. First detection of Drosophila suzukii in European countries (2008-2012)

\begin{tabular}{cll}
\hline First record & Country & Reference \\
\hline 2008 & Italy & RASPI et al. 2011 \\
2008 & Spain & CALABRIA et al. 2012 \\
2009 & France & GrAssi et al. 2009 \\
2011 & Austria & LETHMAYER 2011 \\
2011 & Belgium & EPPO 2012 \\
2011 & Croatia & MiLEK et al. 2011 \\
2011 & Germany & VOGT et al. 2012 \\
2011 & Slovenia & SELJAK 2011 \\
2011 & Swiss & BAROFFIO \& FisHER, 2011 \\
2012 & Hungary & KISS et al. 2013 \\
2012 & The Netherlands & EPPO 2012 \\
2012 & Portugal & EPPO 2012 \\
2012 & United Kingdom & EPPO 2012 \\
\hline
\end{tabular}

flies to enter into the bottle. The bottles were baited with $100 \mathrm{ml}$ apple cider vinegar, which is considered to be highly effective and practical bait for trapping SWD (LeE et al. 2012). The traps were hung on different trees or bushes $1.5 \mathrm{~m}$ above the ground. Three separate trapping periods were conducted in different seasons of the year. The periods lasted for three weeks starting in different highways between 14 and 21 of May in spring, 15 and 19 in July in summer and 16 and 24 of September in autumn.

Monitoring by the National Food Chain Safety Office (NÉBIH) was conducted in various types of orchards (plum, apple, vineyards, cherry etc.); total 29 sites were investigated countrywide. Four funnel traps were used in each county from the mid June to the end of October. The traps were hung on trees of different orchards, $1.5 \mathrm{~m}$ above the ground, in shady places. The baiting liquid consisted of $150 \mathrm{ml}$ red vine, $150 \mathrm{ml}$ apple cider vinegar and a few drops of detergent. This mixture had been changed in every 8-10 days.

\section{RESULTS}

In highway rest areas, we have captured additional specimens of SWD from the locality "Táska" as well as from new sites in autumn of 2013.

New records of Drosophila suzukii (Matsumura, 1931) in Hungary (Fig. 1): 6 females: M7, „Szegerdo"” highway rest area, 16/9-10/10/2013, leg: Kiss, B; 3 males, 14 females: M7, "Táska" highway rest area, 16/9-10/10/2013, leg: Kiss, B; 5 males, 3 females: M7, "Letenye" Croatian-Hungarian border station, 16/9-10/10/2013, leg: Kiss, B; 1 female: M7, "Velence" highway rest area, 16/9-10/10/2013, leg: Kiss, B; 1 female: M1, “Moson" highway rest area, 20/910/11/2013, leg: Kiss, B. 


\section{DISCUSSION}

The circumstances of findings of SWD populations indicate interesting assumptions on these populations as well as on the spreading of the species.

First of all it is noteworthy that only traps placed at highway rest areas were positive for SWD, while many other traps remained negative countrywide (Fig. 1). We cannot state certainly that SWD is not present in other parts that have not been monitored in Hungary, but the role of highways in SWD's rapid spreading looks obvious.

The trapping of D. suzukii was successful only in autumn period, which is in accordance with the phenology of the species experienced in Europe. For instance, in Trentino region, in north-eastern part of Italy, Grassi et al. (2012) found that D. suzukii catches have started in July, and reached their maximum in September and October.

On the other hand, it is interesting that there was no orchard at the collection locality or in the surroundings within the possible flight range of SWD (ca. $7.1 \mathrm{~km}$, based on analogy with D. melanogaster Meigen, 1830 (YERINGTON

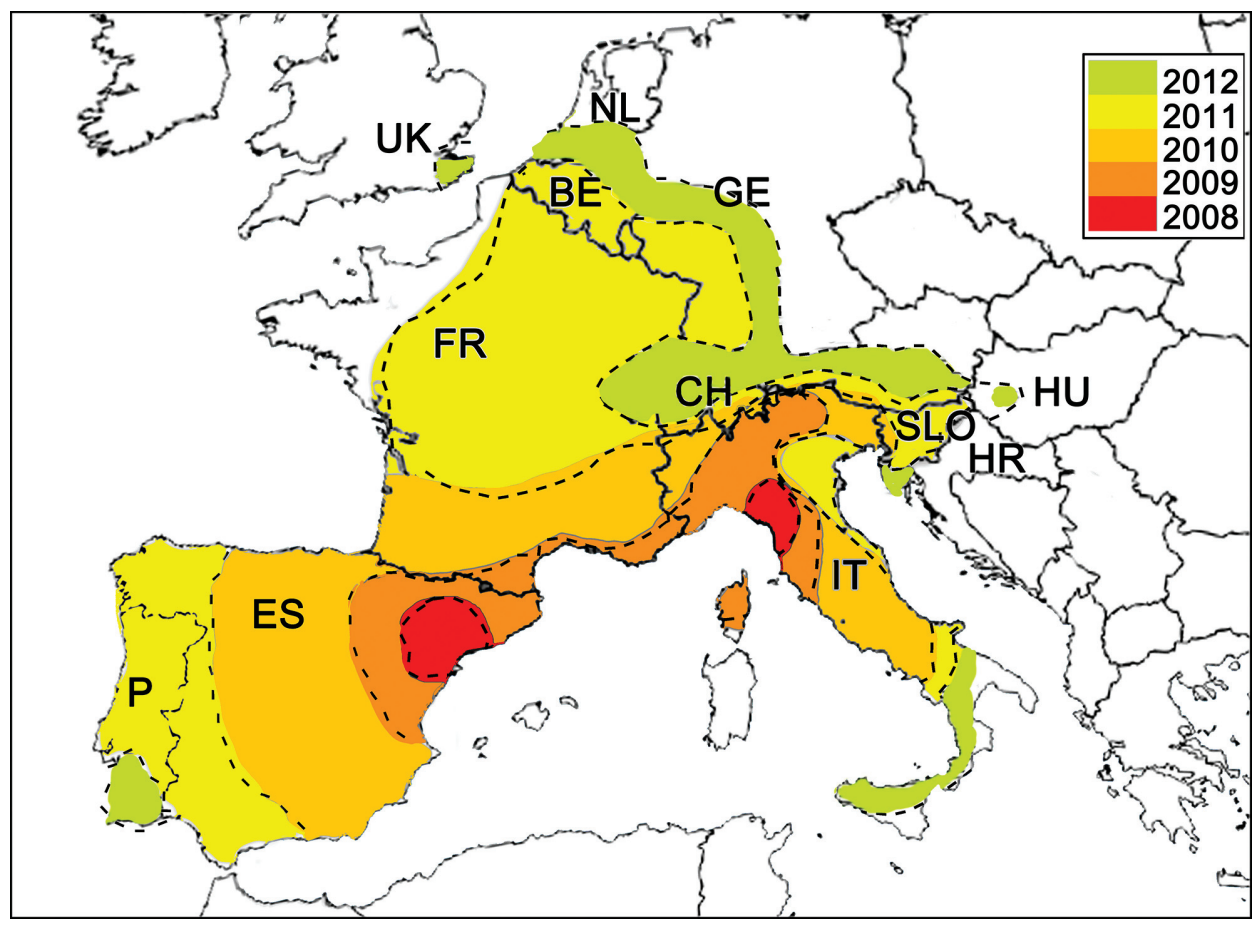

Fig. 2. Hypothetical map of spreading of Drosophila suzukii in Europe based on literature data (CAlabria et al. 2012, Cini et al. 2012, Eppo 2012, Franchi \& Barani 2011, Grassi et al. 2009, Pansa et al. 2011, Seljak 2011, Vogt et al. 2012). 
\& WARnER 1961)). The above mentioned circumstances suggest that the collected flies did not originate from nearby habitats, rather arrived by transport along highways.

To establish a new population, individuals must find a food source quickly at or near the arrival site. Mixed trash bins usually contain rotten fruit or some decaying organic matter, which could act as a food source, but these bins are emptied frequently (twice per week), therefore they are not suitable to sustain a stable fly population. In the case of recycling bins the emptying frequency is much lower: only once a month (AVE Co. Ltd. - pers. comm.), which could be long enough to serve as surviving spots for the population. We found high number of drosophilids inside a recycling bin at the rest area of the first detection of SWD (Fig. 3). This supports our presumption concerning the possible role of these bins in promoting the establishment of new SWD populations, especially as organic waste has also been found in the bins providing suitable food source for breeding drosophilids. However, we have not caught SWD inside the bins and we do not have evidence that SWD uses recycle bins for breeding.

Drosophilids are relatively weak flyers, especially compared to some invasive pests (e.g. Harmonia axyridis Pallas, 1773), however, SWD's rate of

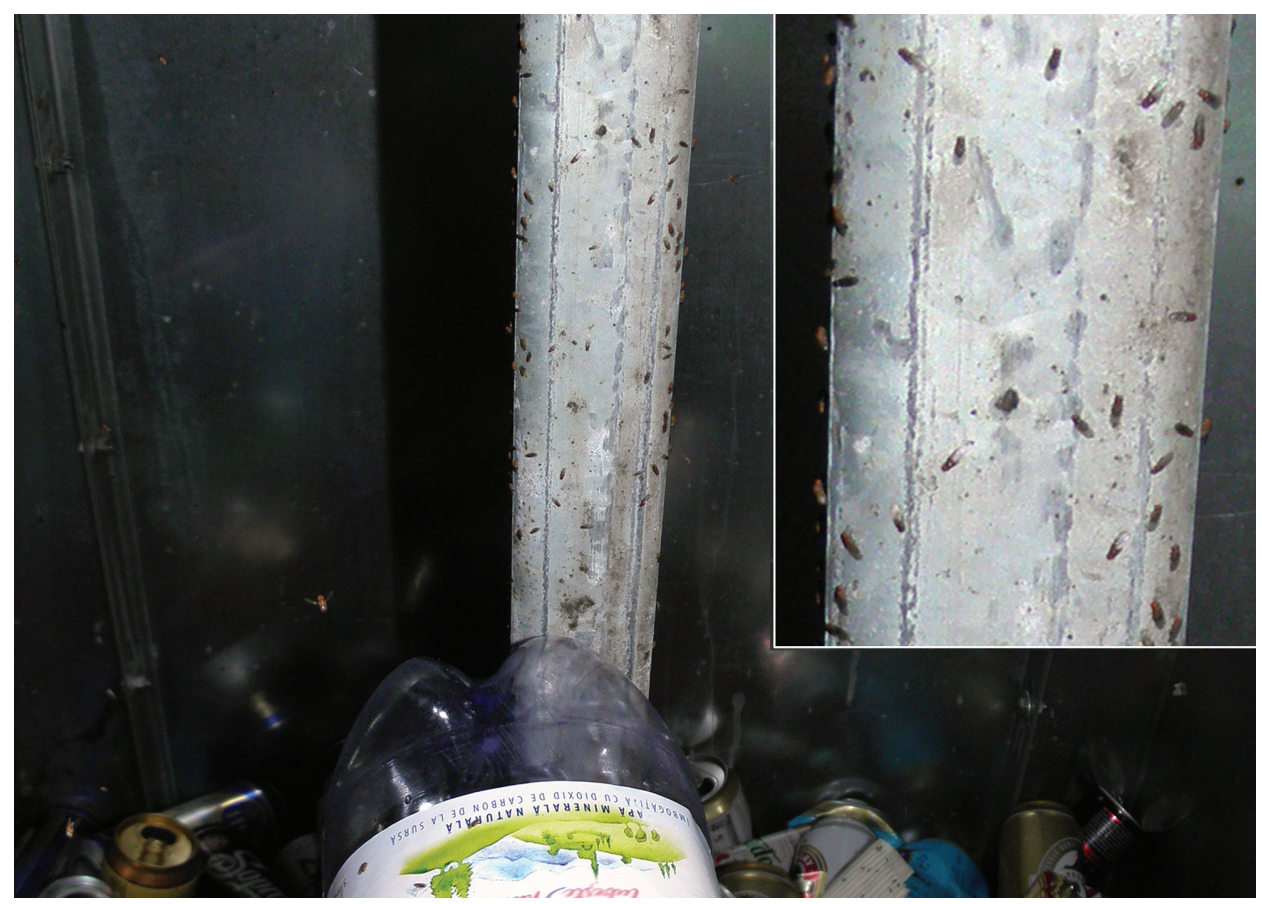

Fig. 3. Drosophilids inside a recycling bin in a highway rest area. 
spread is quite high. We have calculated the maximum rate of spread of SWD at 320-390 $\mathrm{km}$ year-1. This calculation is based on the distance between the first records in Spain (CAlabria et al. 2012) and Italy (RAspi et al. 2011) and the farthest point in Belgium and United Kingdom (2012 EPPO Website). Compared with other introduced invasive insects in Europe, the spread of SWD across Europe is rapid (Fig. 2). For comparison in case of harlequin ladybird (Harmonia axyridis), the rate of spread is approximately $200 \mathrm{~km}^{-1}$ year $^{-1}$ (Brown et al. 2011).

Although the species was recorded from the Alps (e.g. Switzerland) later than from the surrounding countries (Fig. 2), mountainous regions could not prevent the expansion of SWD populations. Due to the scarcity of data, reconstruction of the spreading pattern in Spain is not possible. At the moment it cannot be deduced whether SWD's appearances in Italy and Spain were independent from each other or if SWD has colonized these regions from one locality prior to 2008.

From the sampling results it seems that our findings are very likely one of the first introduced populations in the country and SWD is not widely established in Hungary, yet. According to other experiences (e.g. Vogt et al. 2012) wide colonization of SWD is expected in the near future. Monitoring along highways should be continued because it could supply important data on the presence and spreading pathways of SWD. Our results suggest that monitoring is not only necessary in neighbouring countries of infested areas, but also in more distant ones, due to the rapid and possible "jumping" spread of this species.

Acknowledgements - The authors acknowledge to Martin Hauser for his valuable comments on the manuscript. Our sincere thanks are due to Laurence Livermore for linguistic revision of the manuscript. The project was founded by OTKA K83829, Hungarian Scientific Research Fund PD 1041310, János Bolyai Research Scholarship of the Hungarian Academy of Sciences and Marie Curie-CIG research grant PCIG12-GA-2012-333980 for support of Zsolt Kárpáti. We also thank Alexandra Kis for the technical assistance.

\section{REFERENCES}

Bächli, G. \& Rocha Pité, M. T. (1984) Family Drosophilidae. Pp. 186-220. In: Papp, L. \& Soós, Á. (eds): Catalogue of Palaearctic Diptera. Vol. 10. Akadémiai Kiadó, Budapest.

Baroffio, C. \& Fischer, S. (2011) Neue Bedrohung für Obst-Plantagen und Beerenpflanzen: die Kirschessigfliege. UFA-Revu 11: 46-47.

Brown, P. M. J., Thomas, C., Lombaert, E., Jeffries, D. L., Estoup, A. \& Lawson Handley, L. J. (2011) The global spread of Harmonia axyridis: distribution, dispersal and routes of invasion. BioControl 56: 623-641. 
Calabria, G., Maca, J., Bachli, G., Serra, L. \& Pascual, M. (2012) First records of the potential pest species Drosophila suzukii (Diptera: Drosophilidae) in Europe. Journal of Applied Entomology 136: 139-147. doi: 10.1111/j.1439-0418.2010.01583.x

Cini, A., Ioriatti, C. \& Anfora, G. (2012) A review of the invasion of Drosophila suzukii in Europe and a draft research agenda for integrated pest management. Bulletin of Insectology 65: 149-160.

EPPO - European and Mediterranean Plant Protection Organization www.eppo.org, http:// archives.eppo.int/EPPOReporting/2012/Rse-1210.pdf (Accessed on 01/08/2014)

Franchi, A. \& Barani, A. (2011) Un nuovo agente di danno per frutta e vite in Emilia. Notiziario Fitopatologico 2: 14.

Grassi, A., Palmieri, L. \& Giongo, L. (2009) Nuovo fitofago per i piccoli frutti in Trentino. Terra Trentina 55: 19-23.

Grassi, A., Giongo, L. \& Palmieri, L. (2011) Drosophila (Sophophora) suzukii (Matsumura), new pest of soft fruits in Trentino (North-Italy) and in Europe. IOBC/WPRS Bulletin 70: 121-128.

Grassi, A. \& Pallaoro, M. (2012) Drosophila suzukii (Matsumura) a revolution for soft fruits inTrentino. Ecofruit, 15th International Conference on Organic Fruit-Growing. Proceedings for the Conference, Hohenheim, Germany, 20-22 February 2012, pp. 179-186.

Hauser, M., Gaimari, S. \& Damus, M. (2009) Drosophila suzukii new to North America. Fly Times 43: 12-15.

Hauser, M. (2011) A historic account of the invasion of Drosophila suzukii (Matsumura) (Diptera: Drosophilidae) in the continental United States, with remarks on their identification. Pest Management Science 67: 1352-1357. doi: 10.1002/ps.2265

Kiss, B., Lengyel, G., Nagy, Z. \& Kárpáti Z. (2013) A pettyesszárnyú muslica (Drosophila suzukii) első magyarországi előfordulása. Növényvédelem 49: 97-99.

Lee, C. B., Burrack, H. J., Barrantes, L. D., Beers, E. H., Dreves, A. J., Hamby, K. A., Haviland, D. R., Isaacs, R., Richardson, T. A., Shearer, P. W., Stanley, C. A., Walsh D. W., Walton V. M., Zalom F. G. \& Bruck D. J. (2012) Evaluation of monitoring traps for Drosophila suzukii (Diptera: Drosophilidae) in North America. Journal of Economic Entomology 105: 1350-1357. doi: 10.1603/EC12132

Lethmayer, C. (2011) Gefährliche Fliegen für Äpfel \& Co. Besseres Obst 12: 4-5.

Milek, T. M., SeljaK, G., Šimala, M. \& Bjeliš, M. (2011) First record of Drosophila suzukii (Matsumura, 1931) (Diptera: Drosophilidae) in Croatia. Glasilo Biljne Zaštite 11: 377-382.

Pansa, M. G., Frati, S., Baudino, M., Tavella, L. \& Alma, A. (2011) Prima segnalazione di Drosophila suzukii in Piemonte. Protezione delle Colture 2: 108.

Raspi, A., Canale, A., Canovai, R., Conti, B., Loni, A. \& Strumia, F. (2011) Insetti delle aree protette del comune di San Giuliano Terme. Felici Editore, San Giuliano Terme, Pisa, Italy, $189 \mathrm{pp}$.

Seljak, G. (2011) Spotted wing Drosophila, Drosophila suzukii (Matsumura), a new pest of berry-fruit in Slovenia. Sadjarstvo 22: 3-5.

Steck, G. J., Dixon, W. \& Dean D. (2009) Spotted wing drosophila, Drosophila suzukii (Matsumura) (Diptera: Drosophilidae), a fruit pest new to North America. Pest Alerts http://www.fl.dpi.com/enpp/ento/drosophila_suzukii.html. (Accessed on 01/08/2014).

Vogt, H., Baufeld, P., Gross, J., Kopler, K. \& Hoffmann C. (2012) Drosophila suzukii: eine neue Bedrohung für den europäischen Obst- und Weinbau. Bericht über eine internationale Tagung in Trient, 2, Dezember 2011. Journal für Kulturpflanzen 64: 68-72. 
Walsh, D. B., Bolda, M. P., Goodhue, R. E., Dreves, A. J., Lee, J., Bruck, D. J., Walton, V. M., O’Neal, S. D. \& Zalom, F. G. (2011) Drosophila suzukii (Diptera: Drosophilidae) Invasive pest of ripening soft fruit expanding its geographic range and damage potential. Journal of Integrated Pest Management 2: 1-7. doi: 10.1603/IPM10010

Yerington, A. P. \& WARner, R. M. (1961) Flight distance of Drosophila determined with radioactive phosphorus. Journal of Economic Entomology 54: 425-428. doi: 10.1093/ jee/54.3.425

Revised version received October 17, 2014, accepted January 5, 2015, published April 30, 2015 